\title{
Detección de micobacterias en muestras clínicas mediante la Reacción en Cadena de la Polimerasa
}

\section{Artículo Original}

Anar J. Rodríguez, Sara Palma, Jorge L. Maestre, Diana Saavedra, Teresa Reyes, María Perovani.

Laboratorio de Microbiología Clínica, Instituto de Medicina Tropical "Pedro Kourí", Ciudad de la Habana, Cuba.

\section{RESUMEN.}

Introducción. Las micobacteriosis contituyen un importante problema de salud a nivel mundial, siendo aún mayor en pacientes con el Síndrome de Inmunodeficiencia Adquirida (SIDA). En este trabajo utilizamos la Reacción en Cadena de la Polimerasa (RCP) para el diagnóstico de las principales micobacteriosis, y comparamos los resultados obtenidos con los del diagnóstico convencional.

Material y métodos. Se procesaron cepas controles y 15 muestras: 14 esputos y 1 líquido cefalorraquídeo provenientes de pacientes con sospecha clínica de tuberculosis. El procesamiento de las muestras para la RCP se realizó por calentamiento. Se emplearon oligonucleótidos que amplifican un fragmento del gen de la proteína de $65 \mathrm{kDa}$ de los complejos Mycobacterium tuberculosis y Mycobecterium avium intracellulare (MAI).

Resultados. Ocho muestras resultaron positivas a la RCP revelada por electroforesis sobre gel de agarosa, y 7 resultaron negativas. Los resultados de la RCP y del cultivo micobacteriológico coincidieron en 10 casos.

Discusión. La RCP es una técnica que reduce a horas el tiempo de diagnóstico de micobacteriosis. (Rev Biomed 2000; 11:257-262)

Palabras clave: Reacción en cadena de la polimerasa, micobacteria, mycobacterium tuberculosis, mycobacterium avium intracellulare.

\section{SUMMARY.}

Detection by Polimerase Chain Reaction of mycobacteria in clinical samples.

Introduction. Mycobacterial diseases are an important health problem worldwide technique based on the Polymerase Chain Reaction (PCR) for the diagnosis of mycobacteria of the complexes Mycobacterium tuberculosis and Mycobacterium

Solicitud de sobretiros: Lic. Anar J. Rodríguez-Cheang, Gloria No. 417 bajos, entre Aguila y Revillagigedo, Habana Vieja. La Habana 10200, Cuba. Tel.: 22-06-34 Fax: 33-91-55 
AJ Rodríguez, S Palma, JL Maestre, D Saavedra y col.

avium - intracellulare (MAI), and we compared the obtained results with the results from the conventional diagnosis.

Material and methods. 2 control strains and 15 samples were used: 14 sputum samples and 1 cerebrospinal fluid (CSF) of patients with suspicion of tuberculosis. The samples were processed by the thermic method. Oligonucleotides that amplify the gen of a $65 \mathrm{kDa}$ protein of the complex $\mathrm{M}$. tuberculosis and MAI were used.

Results. Eight samples were positive to the presence of specific mycobacterial DNA and 7 were negative. The results by PCR were corroborated with a mycobacterial culture in 10 cases.

Discussion. This technique reduces the time for the diagnosis of the main mycobacterial diseases.

(Rev Biomed 2000; 11:257-262)

Key words: Polimerase chain reaction, mycobacterial diseases, mycobacterium tuberculosis, mycobacterium avium intracellulare.

\section{INTRODUCCIÓN.}

Las micobacteriosis constituyen uno de los principales problemas de salud en pacientes con SIDA. Los agentes etiológicos más importantes pertenecen a los complejos Mycobacterium aviumintracellulare, detectados en el 50\% de los casos durante la fase tardía de la enfermedad o en la autopsia, y Mycobacterium tuberculosis $(1,2)$, al cual se le adjudica un efecto sinérgico con el virus de la inmunodeficiencia humana (VIH) (3).

El diagnóstico convencional de las micobacterias tiene como desventajas la baja sensibilidad y especificidad del análisis microscópico, su límite inferior de detección es de $10^{4}$ bacilos por mililitro de muestra $(4,5)$, y el lento crecimiento de las micobacterias patógenas en cultivo (6). Sin embargo, la reacción en cadena de la polimerasa (RCP) permite la identificación rápida y específica de las micobacterias (7) con un límite inferior de detección que varía de 1 a 100 bacilos por mililitro de muestra (4).

\section{Revista Biomédica}

Desde su descubrimiento, varios autores han empleado la RCP para la detección de $M$. tuberculosis. Para estos estudios se han usado iniciadores que amplifican diferentes elementos genéticos, como la secuencia de inserción IS6110 (8-10), el gen que codifica para el antígeno de 65 kDa (11-13), y el de 38 kDa $(14,15)$ y han desarrollado diferentes métodos de procesamiento de las muestras, amplificación y detección del ADN amplificado.

Entre los métodos de descontaminación de las muestras clínicas que con más frecuencia son utilizados, está el protocolo estándar del $\mathrm{NaOH}$ $\mathrm{N}$-acetilcisteína $(13,17)$ y el protocolo del lauril sulfato de sodio (14-16), el cual ha mostrado resultados comparables con los del NaOH-Nacetilcisteína (14). La ruptura celular puede hacerse por un método térmico (11), enzimático, mecánico o mixto $(8,12,14,16,17)$.

Los productos de la RCP pueden visualizarse por hibridación del producto amplificado con una sonda específica de ácido nucleico y detección colorimétrica $(8-10,16,17)$, por electroforesis en gel de poliacrilamida (3), y electroforesis en gel de agarosa teñido con bromuro de etidio $(4,6,10$, 14), entre otros métodos.

En el presente trabajo realizamos un estudio experimental de la aplicación de la RCP al diagnóstico de las micobacteriosis en muestras clínicas de esputo y líquido cefalorraquídeo, proveniente de pacientes con SIDA e inmunocompetentes, y comparamos los resultados con los arrojados mediante la aplicación de métodos convencionales.

\section{MATERIALES Y MÉTODOS.}

Cepas controles: Se usaron como controles las cepas Mycobacterium tuberculosis H37RV y Mycobacterium avium clasificada por el Laboratorio Biológico Farmacéutico (LABIOFAM), Ciudad de La Habana, Cuba.

Procesamiento de las muestras: Se emplearon para el estudio 15 muestras clínicas: 14 esputos y 
Detección de micobacterias por reacción en cadena de la polimerasa.

1 líquido cefalorraquídeo, procedentes de pacientes con SIDA e inmunocompetentes que presentaban un cuadro clínico sospechoso de tuberculosis. A todas se les practicó el examen directo de los frotis teñidos por Ziehl-Neelsen, y se procedió a la descontaminación de los esputos usando hidróxido de sodio (18). Luego los esputos licuados, el líquido cefalorraquídeo y las cepas controles fueron procesados para la RCP por el método térmico que describimos a continuación.

Procesamiento por calor: En cada caso se tomaron $500 \mu \mathrm{l}$ de muestra, se centrifugó y se lavó el sedimento con tampón Tris-EDTA (TE) pH 8, resuspendiéndolo al final en $50 \mu \mathrm{l}$ del tampón. La ruptura celular se efectuó por calentamiento en baño de agua a $100^{\circ} \mathrm{C}$ durante 10 minutos (11).

Iniciadores: Los iniciadores usados para la amplificación fueron descritos por Rodrigo y colaboradores (3). Los mismos amplifican un fragmento de $383 \mathrm{pb}$ del gen que codifica para la proteína de $65 \mathrm{kDa}$ de Mycobacterium tuberculosis / M. bovis BCG y M. avium / M. intracellulare. Estos fueron sintetizados en el Centro de Ingeniería Genética y Biotecnología (CIGB), Ciudad de La Habana, Cuba.

Procedimiento de la RCP: La RCP fue realizada en un termociclador programable (MJ Research Inc. Watertown, M.A., USA). La mezcla de reacción contuvo 25 pmol de cada iniciador (CIGB), 2,5 U de enzima TAQ polimerasa, $50 \mathrm{mM}$ de $\mathrm{KCl}$, $10 \mathrm{mM}$ de Tris-HCl pH 9, 0,1\% de TRITON X100 y $1,5 \mathrm{mM}$ de $\mathrm{MgCl} 2$ (Perkin Elmer Cetus, Norwalk, CT, USA), 0,3 mM de deoxinucleótidos (Boehringer Mannheim GmbH, Mannheim, Germany) y $5 \mu$ de muestra, para un volumen final de $50 \mu \mathrm{l}$ (3). Se usó el siguiente programa de amplificación, desarrollado por los autores: desnaturalización 4 minutos a $95^{\circ} \mathrm{C}, 30$ ciclos de desnaturalización 1 minuto a $95^{\circ} \mathrm{C}$, hibridación 1 minuto a $57^{\circ} \mathrm{C}$ y extensión 2 minutos a $72^{\circ} \mathrm{C}$, con un tiempo de extensión final de 10 minutos a $72^{\circ} \mathrm{C}$.
Electroforesis en gel de agarosa: Se hizo una electroforesis en gel de agarosa al $2 \%$ teñido con bromuro de etidio, utilizando $10 \mu \mathrm{l}$ de los productos amplificados. Los resultados se visualizaron mediante la observación del gel en un transiluminador de luz ultravioleta.

Muestras de cada uno de los pacientes estudiados fueron enviadas al Laboratorio de Referencia Nacional de Tuberculosis para realizarles el cultivo micobacteriológico.

\section{RESULTADOS.}

De las 15 muestras estudiadas, 8 resultaron positivas a la RCP y 7 resultaron negativas (fig. 1 y 2). Hubo 3 muestras que resultaron positivas por RCP, examen directo y cultivo micobacteriológico, aislándose de ellas Mycobacterium tuberculosis; 2 positivas a la RCP y al examen directo, pero negativas al cultivo; 3 muestras que provenían de pacientes inmunodeprimidos con alta sospecha clínica de tuberculosis, fueron positivas a la RCP y negativas a los métodos convencionales; 5 resultaron negativas por todos los métodos; y 2 muestras resultaron negativas a la RCP, positivas al examen directo, y mediante el cultivo se aislaron de ellas micobacterias atípicas no MAI (cuadro 1).

\section{DISCUSIÓN.}

La detección directa de agentes infecciosos en material clínico es una atractiva posibilidad en el diagnóstico rápido de enfermedades, especialmente las causadas por agentes cuyo crecimiento en cultivo es difícil o lento, como por ejemplo las micobacterias (4).

Recientemente el cultivo radiométrico ha disminuido el tiempo de aislamiento de las micobacterias y del análisis de susceptibilidad; sin embargo, resulta muy caro para las posibilidades de los laboratorios clínicos, y requiere el uso de material radioactivo (13).

La amplificación de moléculas blanco a un nivel detectable, por la RCP, constituye el mejor

Vol. 11/No. 4/Octubre-Diciembre, 2000 
AJ Rodríguez, S Palma, JL Maestre, D Saavedra y col.

Cuadro 1

Resultados obtenidos mediante las técnicas de la reacción en cadena de la polimerasa, el examen directo y el cultivo a partir de muestras de esputo y líquido cefalorraquídeo.

\begin{tabular}{ccccc}
\hline No. de muestra & $\begin{array}{c}\text { Naturaleza de } \\
\text { muestra }\end{array}$ & $\begin{array}{c}\text { Resultado de } \\
\text { RCP }\end{array}$ & $\begin{array}{c}\text { Resultado del } \\
\text { examen directo }\end{array}$ & $\begin{array}{c}\text { Resultado del } \\
\text { cultivo }\end{array}$ \\
\hline 1 & Esputo & + & + & $+^{\mathrm{a}}$ \\
2 & Esputo & + & + & $+^{\mathrm{a}}$ \\
3 & Esputo & + & + & $+^{\mathrm{a}}$ \\
4 & Esputo & + & + & $-^{\mathrm{c}}$ \\
5 & Esputo & + & - & - \\
6 & Esputo & + & - & - \\
7 & Esputo & + & - & - \\
8 & Esputo & + & - & - \\
9 & Esputo & - & - & - \\
10 & LCR & - & - & - \\
11 & Esputo & - & - & - \\
12 & Esputo & - & - & $+^{\mathrm{b}}$ \\
13 & Esputo & - & + & $+^{\mathrm{b}}$ \\
14 & Esputo & - & + & - \\
15 & Esputo & - & + & + \\
\hline
\end{tabular}

+ Presencia del producto específico amplificado, de bacterias ácido-alcohol-resistentes o de micobacterias según el método de RCP, examen directo y cultivo, respectivamente.

- Ausencia del producto específico amplificado, de bacterias ácido-alcohol-resistentes o de micobacterias.

a Aislamiento de M. tuberculosis.

${ }^{\mathrm{b}}$ Aislamiento de micobacterias atípicas no Mycobacterium avium intracellulare.

${ }^{\mathrm{c}}$ No crecimiento de micobacterias y crecimiento de contaminantes.

sistema desarrollado para la detección de micobacterias. Esta técnica no sólo es altamente sensible y rápida, sino que permite identificar las especies de micobacterias si usamos los iniciadores específicos (13).

En el presente trabajo desarrollamos una técnica de RCP para detectar micobacterias en muestras clínicas. La misma es sencilla, rápida y económica, adaptada a los escasos recursos y la dinámica de un laboratorio clínico. El procesamiento previo de las muestras sólo consta de tres pasos: descontaminación, lavado con el tampón Tris-EDTA (TE) $\mathrm{pH} 8$ y ruptura celular por calentamiento en baño de agua a $100^{\circ} \mathrm{C}$. Por otra parte, los oligonucleótidos utilizados son de producción nacional, y el método de revelado de los resultados Revista Biomédica de la RCP es una simple electroforesis sobre gel de agarosa.

En el estudio realizado se encontró que en 10 muestras los resultados obtenidos por los tres métodos concuerdan perfectamente. En el caso de las 2 muestras en que el examen directo es positivo y se observa crecimiento en cultivo de micobacterias atípicas no MAI, la RCP es negativa, porque los oligonucleótidos amplifican un fragmento del gen que codifica para la proteína de 65 $\mathrm{kDa}$ de micobacterias pertenecientes a estos dos complejos solamente: M. tuberculosis y M. avium - intracellulare; no se incluyen las otras micobacterias atípicas.

Por otra parte, hubo 2 muestras positivas al examen directo y a la RCP con cultivos negativos 
Detección de micobacterias por reacción en cadena de la polimerasa.
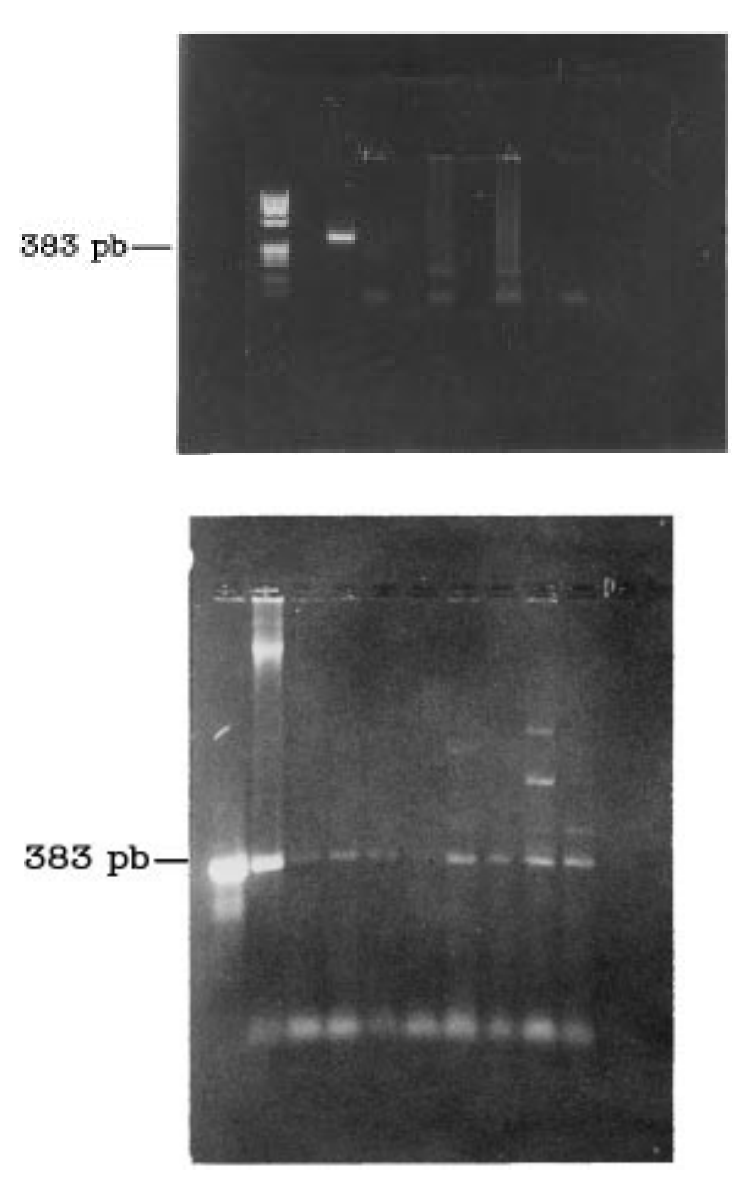

Fig. 1 y 2.- Electroforesis en gel de agarosa teñido con bromuro de etidio de los productos de la RCP a partir de 15 muestras clínicas: 14 esputos y 1 líquido cefalorraquídeo y suspensiones de dos cepas controles, procesadas por calentamiento.

Fig. 1 Línea 1: Marcador de peso molecular ( 174 digerido con Hae III. Línea 2: Control de reactivos. Línea 3: Producto específico de $383 \mathrm{pb}$ amplificado a partir del control de M. tuberculosis. Líneas 4, 6, 7, 8,9 y 10: Ausencia del producto específico amplificado en muestras de esputo. Línea 5: Ausencia del producto específico amplificado en la muestra de líquido cefalorraquídeo. Líneas 6 y 8: Se observan bandas claras, cuya talla no corresponde a 383 pb y por tanto, son resultado de amplificación inespecífica.

Fig. 2 Líneas 1 y 2: Se observan fragmentos de ADN de 383 pb provenientes de la RCP que se realizó a las cepas controles de $M$. tuberculosis y $M$. avium respectivamente. Líneas 3, 4, 5, 6, 7, 8, 9 y 10: Presencia del producto específico amplificado. Líneas 2, 7, 9 y 10: Se observan bandas adicionales que corresponden a amplificación inespecífica. En la línea 6, el producto de la RCP fue visto como una banda muy tenue, la que no se aprecia claramente en la fotografía del gel. con crecimiento de contaminantes. Las mismas procedían de pacientes, de los que posteriormente se han obtenido cultivos positivos de Mycobacterium tuberculosis. Esto sugiere que la RCP puede ser más sensible que el cultivo en la detección de pocos microorganismos viables, lo cual ya ha sido descrito por otros autores $(6,7)$.

En 3 casos con una fuerte sospecha clínica de tuberculosis, sólo la RCP fue positiva. Uno de estos pacientes está recibiendo tratamiento específico con una evidente mejoría de los síntomas, y en los otros 2 casos se ha asumido una conducta conservadora respecto a la terapéutica farmacológica hasta obtenerse algún cultivo positivo. No obstante a las evidencias clínicas, por el momento consideramos los mismos como posibles falsos positivos, fenómeno que pudiera deberse a la contaminación cruzada entre las muestras. Este fenómeno fue analizado por Noordhoek y colaboradores (19) como uno de los principales responsables de la variabilidad de los resultados de la RCP en una estudio comparado realizado en siete laboratorios, a los que se enviaron las mismas muestras.

En los geles se observan bandas adicionales que no se corresponden con la talla del fragmento estudiado; esto desdice de la especificidad de esta técnica, y sería conveniente realizar alguna estrategia para optimizar la RCP, como por ejemplo: aumentar la temperatura de hibridación, disminuir la concentración de enzima en la mezcla de reacción, disminuir el tiempo de hibridación y/o el de elongación, así como el número de ciclos.

En conclusión, la técnica basada en la RCP que utilizamos en este trabajo pudiera emplearse para el diagnóstico de micobacteriosis en un laboratorio clínico, teniendo en cuenta las recomendaciones de los autores.

\section{REFERENCIAS.}

1. Brisson-Noel A, Aznar C, Chureau C, Nguyen S, Pierre $\mathrm{C}$, Bartole M, et al. Diagnosis of tuberculosis by DNA amplification in clinical practice evaluation. Lancet. 1991; 338:364-6.

Vol. 11/No. 4/Octubre-Diciembre, 2000 


\section{AJ Rodríguez, S Palma, JL Maestre, D Saavedra y col.}

2. Telenti A, Marchesi F, Balz M, Bally F, Böltger EC, Bodner T. Rapid identification of Mycobacterium to the species level by polymerase chain reaction and restriction enzyme analysis. J Clin Microbiol 1993; 31:175-8.

3. Rodrigo G, Källenius G, Hoffmann E, Svenson SB. Diagnosis of Micobacterial Infections by PCR and Restriction Enzyme Digestion. Letters in Applied Microbiology 1992; 15: 41-4.

4. Folgueira L, Delgado R, Palenque E, Noriega AR. Detection of Mycobacterium tuberculosis DNA in clinical samples by using a simple lysis method and polymerase chain reaction. J Clin Microbiol 1993; 31: 1019-21.

5. Sjobring U, Mecklenburg M, Andersen AB, Miörner H. Polymerase chain reaction for detection of Mycobacterium tuberculosis. J Clin Microbiol 1990; 28: 2200-4.

6. Kulski JK, Pryce T. Preparation of Mycobacterial DNA from blood culture fluids by simple alkali wash and heat lysis method for PCR detection. J Clin Microbiol 1996; 34: 1985-91.

7. Pozniak A, Watson JN. Nosocomial transmision of tuberculosis in AIDS care centres. Communicable Disease Report 1992; 2: 71-2.

8. Klatser PR. Amplification reactions in mycobacteriology. J Microbiol Methods 1995; 23: 75-87.

9. Bennedsen J, Thomsen VO, Pfyffer GE, Funke G, Feldmann K, Beneke A, et al. Utility of PCR in diagnosing pulmonary tuberculosis. J Clin Microbiol 1996; 34: 140711.

10. Tevere VJ, Hewitt PR, Dare A, Hocknell P, Keen A, Padoro JPS, et al. Detection of Mycobacterium tuberculosis by PCR amplification with pan-Mycobacterium primers and hybridization to an M. tuberculosis - specific probe. J Clin Microbiol 1996; 34: 918-23.

11. Kocagöz T, Yilmaz E, Özkara S, Kokagöz S, Hayran M, Sachedeva M, et al. Detection of Mycobacterium tuberculosis in sputum samples by polymerase chain reaction using a simplified procedure. J Clin Microbiol 1993; 31: 1435-8.

12. Wobeser WL, Krajden M, Conly J, Simpson H, Yim B, Costa M, et al. Evaluation of Roche Amplicor PCR assay for Mycobacterium tuberculosis. J Clin Microbiol 1996; 34:134-9.

\section{Revista Biomédica}

13. Clarridge JE, Shawar RM, Shinnick TM, Plikaytis BB. Large-scale use of polymerase chain reaction for detection o Mycobacterium tuberculosis in a routine mycobacteriology laboratory. J Clin Microbiol 1993; 31: 2049-56.

14. Eisenach KD, Sifford MD, Cave MD, Bates JH, Crawford JT. Detection of Mycobacterium tuberculosis in sputum samples using a polymerase chain reaction. Am Rev Respir Dis 1991; 144: 1160-3.

15. Forbes BA, Hicks KE. Ability of PCR assay to identify Mycobacterium tuberculosis in BACTEC R B vials. J Clin Microbiol 1994; 32: 1725-8.

16. Devallois A, Legrand E, Rastogi N. Evaluation of AMPLICOR MTB test as a adjunct to smears and culture for direct detection of Mycobacterium tuberculosis in the French Caribbean. J Clin Microbiol 1996; 34: 1065-8.

17. Bergmann JS, Woods GL. Clinical evaluation of the Roche AMPLICOR PCR Mycobacterium tuberculosis test for detection of M. tuberculosis in Respiratory Specimens. J Clin Microbiol 1996; 34: 1083-5.

18. Lennette EH, Balows A, Hasuler WJ, Truant JP. Microbiología Clínica. 3ra. edición. México: Interamericana; 1983.

19. Noordhoek GT, Kolk AH, Bjune G, Catty D, Dale JW, Fine PE, et al. Sensitivity and Specificity of PCR for detection of Mycobacterium tuberculosis: A blind comparison study among seven laboratories. J Clin Microbiol 1994; 32: 277-84. 